\title{
Percent of Prostate Cores Positive for
} Carcinoma

National Cancer Institute

\section{Source}

National Cancer Institute. Percent of Prostate Cores Positive for Carcinoma. NCl

Thesaurus. Code C150366.

The number of prostate core biopsy samples positive for carcinoma divided by the total number of prostate core samples. 